\title{
TOXICIDADE DOS METAIS NÍQUEL E COBRE E SUA POSSÍVEL ATUAÇÃO COMO INTERFERENTES ENDÓCRINOS EM AMBIENTES AQUÁTICOS
}

TOXICITY OF NICKEL AND COPPER METALS AND THEIR POTENTIAL

PERFORMANCE AS ENDOCRINE DISRUPTORS IN AQUATIC ENVIRONMENTS

\section{Glaucia Helena Castro \\ de Freitas Novaes (iD)}

Mestranda do curso de Ciências

Ambientais da Universidade Estadual

Paulista "Júlio de Mesquita Filho"

(UNESP ICTS) - Sorocaba (SP), Brasil.

\section{Bianca Cadurim Aureliano (iD)}

Graduanda do curso de Engenharia

Ambiental da Universidade Estadual Paulista "Júlio de Mesquita Filho" (UNESP ICTS) - Sorocaba (SP), Brasil.

\section{Evelise Nunes}

Fragoso-Moura (1)

Professora Adjunta. Doutora em Ecologia e Recursos Naturais da Universidade Federal de São Carlos (UFSCar) - São Carlos (SP), Brasil.

\section{Werbate Cavalcante (iD}

Graduando do curso de Engenharia Ambiental da Universidade Estadual Paulista "Júlio de Mesquita Filho" (UNESP ICTS) - Sorocaba (SP), Brasil.

\section{Renata Fracácio}

Professora Assistente Doutora. Doutorado em Ecologia e Recursos Naturais da Universidade Estadual Paulista "Júlio de Mesquita Filho" (UNESP ICTS) - Sorocaba (SP), Brasil.

\section{Endereço para correspondência:}

Renata Fracácio - Avenida Três de Março, 511, 30 andar, sala 59Aparecidinha-CEP 18087-180Sorocaba (SP), Brasil E-mail: rfracacio@sorocaba.unesp.br

Recebido em: 01/02/2018

Aceito em: 16/07/2018

\section{RESUMO}

Apesar de serem originados de fontes naturais, o níquel é muito utilizado na produção de equipamentos e materiais de construção e o cobre é empregado em fios elétricos, canos, automóveis. Os metais cobre e níquel são conhecidos pelo seu potencial tóxico ao ambiente aquático, além de serem elementos bioacumulativos e persistentes. $O$ presente trabalho teve como objetivos principais: 1 ) testar a toxicidade dos metais cobre e níquel; 2) avaliar o potencial como interferente endócrino dos referidos metais. Diante do exposto, foram realizados testes crônicos utilizando o organismo-modelo Danio rerio durante 21 dias de exposição com os metais cobre $(9 \mu \mathrm{g} / \mathrm{L})$ e níquel $(25 \mu \mathrm{g} / \mathrm{L})$ em regime semiestático, com troca total da água a cada 72 horas, temperatura de $25^{\circ} \mathrm{C}$, com alimentação uma vez ao dia. Posteriormente, os organismos foram eutanasiados e destinados ao procedimento de histologia com inclusão na parafina, coloração com hematoxilina e eosina (HE), para análises morfológicas de gônadas e fígado, utilizando microscópio de luz. Ambos os metais apresentaram alterações morfológicas nos tecidos hepáticos; o níquel mostrou ser potencialmente um interferente endócrino, podendo comprometer o desenvolvimento da espécie e, consequentemente, da homeostase do ecossistema.

Palavras-chave: teste crônico; Danio rerio; tecido gonadal; alterações morfológicas; tecido hepático; ecossistema aquático.

\section{ABSTRACT}

Although they originate from natural sources, nickel is widely used in the production of equipment, building materials and copper used in electric wires, pipes, and automobiles. These metals are known for their potential toxicity to the aquatic environment in addition to being bioaccumulative and persistent elements. The main objectives of this study are: 1) to test the toxicity of copper and nickel metals; 2 ) to evaluate the potential as an endocrine interferent of said metals. In view of the above, chronic tests were carried out using the model organism Danio rerio for 21 days of exposure with copper $(9 \mu \mathrm{g} / \mathrm{L})$ and nickel $(25 \mu \mathrm{g} / \mathrm{L})$ metals in a semi-static regime, with total water exchange at every 72 hours, at a temperature of $25^{\circ} \mathrm{C}$, fed once a day. Subsequently, the organisms were euthanized and destined to the histology procedure with inclusion in paraffin, staining with Hematoxylin and Eosin (HE) for morphological analysis of gonads and liver using light microscope. Both metals presented morphological alterations in hepatic tissue and nickel could potentially act as an endocrine disruptor, able to compromise the development of the species and consequently the ecosystem homeostasis.

Keywords: chronic test; Danio rerio; gonadal tissue; morphological alterations; hepatic tissue; aquatic ecosystem. 


\section{INTRODUÇÃO}

A água é um bem natural e essencial para os organismos aquáticos assim como para todas as formas de vida na terra; dessa forma, seu uso deve ser consciente, para garantir as funções biológicas dos organismos. Estudar os efeitos dos poluentes aquáticos é fundamental para assegurar o desenvolvimento sustentável e garantir a homeostase do sistema (WHO, 2011; ROSA et al., 2011).

O cobre atualmente é utilizado em ligas, canos, fios elétricos, radiadores e automóveis, majoritariamente em atividades de mineração e fundição. O níquel é empregado na produção de equipamentos, aço inoxidável, materiais de construção, equipamentos médicos, contêineres, baterias, cerâmicas, joias e ímã (SARGENTELLI et al., 1995; PEDROZO \& LIMA, 2001; RECK et al., 2008; PYLE \& COUTURE, 2012).

Há diversas evidências na literatura do potencial tóxico do níquel. Em Oncorhynchus mykiss (TOPAL et al., 2017), Hypophthalmichthys molitrix (ATHIKESAVAN et al., 2006) e Prochilodus lineatus (PALERMO et al., 2015) foram observadas alterações nos tecidos das brânquias, como espessamento lamelar, infiltração celular, fusão da segunda lamela, distorção, hipertrofia, hiperplasia e acumulação do metal nos tecidos.

Em Oncorhynchus mykiss submetidos à concentração de 1 a $2 \mathrm{mg} / \mathrm{L}$ de níquel foi verificada a degeneração dos hepatócitos no fígado (TOPAL et al., 2017), além de sinais de estresse oxidativo (ZHENG et al., 2014).

Diversas análises histológicas determinaram o potencial tóxico do cobre em peixes teleósteos. Observando as alterações no tecido das brânquias de Solea senegalensis, foram verificadas alterações nas células pavimentosas, hiperplasia, necrose e apoptose (ARELLANO et al., 1999), também observadas em estudos posteriores em Danio rerio (LUZIO et al., 2013) e Luciobartus bocagei (FONSECA et al., 2017). Ainda analisando tecidos branquiais, Dang et al. (2000) observaram indução da proteína metalotioneína e acúmulo do metal referido (DE BOECK et al., 2006).

Em análises do tecido hepático em peixes, constataram-se alteração no sinusoide, aumento da gotícula lipídica e estagnação sanguínea (ARELLANO et al., 1999). Hauser-Davis et al. (2014) também observaram presença de metalotioneína na bile assim como nos tecidos branquiais analisados.

Ambos os metais causam uma série de mudanças na estrutura celular e fisiológica dos peixes e, por isso, há regulamentações que asseguram a concentração permitida para o lançamento. No Brasil, o Conselho Naciona do Meio Ambiente (CONAMA) determina que podem ser lançados $9 \mu \mathrm{g} / \mathrm{L}$ de cobre e $25 \mu \mathrm{g} / \mathrm{L}$ de níquel em rios de Classe 2, ou seja, aqueles destinados ao abastecimento para consumo humano, após tratamento convencional; à proteção das comunidades aquáticas; à recreação; à irrigação de hortaliças, plantas frutíferas e de parques, com os quais o público tem contato direto; e à aquicultura e à atividade de pesca (BRASIL, 2005).

Muitas vezes, as concentrações permitidas pela legislação não são seguras para a vida aquática em longo prazo. Para caracterizar o efeito dos poluentes nesse contexto, são feitos ensaios ecotoxicológicos crônicos, baseados em respostas biológicas, denominadas biomarcadores, que vão determinar possíveis alterações causadas pelas substâncias tóxicas. Uma das maneiras de avaliar essas respostas pode ser por meio de alterações histológicas no fígado de peixes teleósteos, por ser um órgão sensível a contaminantes (como metais) e tender a acumulá-los em seu interior, fazendo com que as concentrações sejam aumentadas no organismo (HEATH, 1995; SANCHEZ, 2006; AU, 2004). Na revisão feita por $\mathrm{Au}$ (2004), foi realizado um levantamento da correlação entre lesões no fígado de peixes e químicos contaminantes, incluindo metais.

Biomarcadores do fígado são muito utilizados em testes ecotoxicológicos, por ser um órgão multifuncional e importante para os organismos. Dentre suas funções podemos destacar a digestão e o metabolismo, o armazenamento de nutrientes, a formação da bile, a excreção de compostos exógenos tóxicos, a síntese do colesterol, a secreção de lipídeos, entre outras. É um dos órgãos mais afetados quando os organismos são expostos a contaminantes por ser responsável pela sua detoxificação. Portanto, é considerado um órgão-alvo para diversos estudos de parâmetros ambientais e biológicos (HEATH, 1995; CAMARGO \& MARTINEZ, 2007; GAYÃO, 2009). 
Quando peixes são expostos a substâncias tóxicas, é possível observar as seguintes alterações histopatológicas nesse órgão: vacuolização citoplasmática, deslocamento nuclear, degeneração, hipertrofia, atrofia, hiperplasia, necrose, polimorfismo nuclear, parênquima heterogêneo, hepatócitos na periferia das células, vesículas no interior do citoplasma, estagnação sanguínea e biliar e desarranjo dos cordões hepáticos (FERNANDES et al., 2008; GAYÃO, 2009; PEREIRA, 2014; ALKIMIN, 2016; CORRÊA, 2016).

Há organismos conhecidos pela comunidade científica, com sua biologia descrita na literatura, como o peixe tido como organismo-modelo, utilizado no presente estudo, denominado de Danio rerio. Este é conhecido por ser sensível a agentes químicos e, tendo essa sensibilidade constante, garante a repetibilidade e a reprodutibilidade dos resultados, além de possuir sua biologia conhecida e protocolos já estabelecidos pela Organização para a Cooperação e Desenvolvimento Econômico - OECD (DOMINGUES \& BERTOLETTI, 2006).

Em Danio rerio foram observados diminuição da atividade locomotora, retardo no tempo de eclosão e mortalidade, quando expostos a 7,5 a $15 \mathrm{mg} / \mathrm{L}$ de níquel (KIENLE et al., 2008), alterações nas brânquias (LUZIO et al., 2013) e alterações no tecido do sistema endócrino ocasionadas pela exposição de outros metais, como cádmio (0,25 a $1 \mu \mathrm{g} / \mathrm{L})$ e zinco (120 a $180 \mu \mathrm{g} / \mathrm{L})$ (ALKIMIN, 2016).

Em relação ao cobre exposto ao organismo Danio rerio, notaram-se sinais de estresse oxidativo, efeitos genotóxicos e comportamentais (no estágio larval), além de o metal ter efeito acumulativo no fígado e nas brânquias (CRAIG et al., 2007; LEITE et al., 2013; ACOSTA et al., 2016). Luzio et al. (2013) ainda relataram a indução da apoptose celular nas brânquias do organismo quando expostas a concentrações entre 12,5 e $100 \mu \mathrm{L}$ de cobre.

Algumas substâncias são capazes de desregular os hormônios naturais em sua ação, produção, liberação, metabolismo e transporte, podendo provocar mudanças nas fases de reprodução e desenvolvimento ou na maneira como os indivíduos respondem ao estresse. Tais alterações podem durar depois do período de exposição ou então ser passadas a gerações futuras, dependendo das características dos contaminantes (MONNERET, 2017). Essas substâncias são chamadas de interferentes endócrinos (IEs) e essa vertente tem provocado interesse nos pesquisadores (PREDA et al., 2012; KABIR et al., 2015; USEPA, 2017).

A secreção dos hormônios gonadotróficos depende da resposta do peixe aos estímulos ambientais, ou seja, um IE pode alterar a determinação sexual - por exemplo, somente uma fêmea adulta pode induzir a vitelogênese por intermédio da secreção suficiente de estrógeno, porém, perturbações ambientais, como a ação de um IE, podem fazer com que machos também produzam vitelogenina, o que indica feminilização dos indivíduos machos (ISMAIL et al., 2017).

Na revisão de Handy (2003), é evidenciado que o cobre é um interferente endócrino do ecossistema aquático. A exposição crônica a esse metal envolve ajustes fisiológicos em muitos sistemas corporais. As respostas à exposição podem ser classificadas em três grupos: regulação das enzimas e metabolismo, respostas hematopoiéticas e alterações no tecido celular.

Já quanto ao níquel há poucas evidências que possam comprovar que este é um interferente endócrino por falta de informações nas bases de dados atuais. Porém, há artigos que relatam o retardo no tempo de eclosão dos ovos de Danio rerio (KIENLE et al., 2008) e em Pimephales promelas foi verificada a alteração na gônada feminina, sendo observadas diminuição da abundância dos folículos vitelogênicos maduros, atresia folicular e diminuição da fecundidade (DRIESSNACK et al., 2017).

A Agência de Proteção Ambiental Americana (United States Environmental Protection Agency - EPA) delimita a concentração de $2,0 \mu \mathrm{g} / \mathrm{L}$ para exposição aguda e de 1,3 $\mathrm{\mu g} / \mathrm{L}$ de cobre dissolvido para exposição crônica, para garantir a qualidade da água. Nota-se que o padrão é muito menor do que o previsto pela legislação brasileira (9 $\mathrm{\mu g} / \mathrm{L}$ ). Em compensação, o níquel possui valores mais permissíveis na legislação internacional, a qual permite $52 \mu \mathrm{g} / \mathrm{L}$, enquanto o valor estabelecido pela legislação brasileira é de $25 \mu \mathrm{g} / \mathrm{L}$. Todas as concentrações citadas acima são valores subletais, ou seja, não provocam a morte dos indivíduos, porém podem causar danos em seus sistemas fisiológicos de modo que afetem uma população ou comunidade. Portanto, o presente estudo visou a avaliar os efeitos tóxicos e de interferência endócrina dos metais cobre e níquel em concentrações crônicas que possam comprometer a qualidade da vida aquática em longo prazo. 


\section{OBJETIVOS}

O presente trabalho teve como objetivo contribuir com informações a respeito do potencial efeito tóxico em concentrações legais dos metais cobre e ní- quel, bem como avaliar o seu efeito como interferente endócrino das substâncias estudadas em concentrações subletais.

\section{MATERIAIS E MÉTODOS}

\section{Cultivo e manutenção do organismo-teste}

Adultos de Danio Rerio foram mantidos em condições laboratoriais controladas (ABNT, 2015). Manteve-se $1 \mathrm{~g}$ de peixe por L. Utilizou-se água de abastecimento público previamente filtrada em filtros de carvão ativado e por uma tela tipo silkscreen. Essa água foi mantida por aeração para remoção do cloro por um período de 24 horas. A dureza foi mantida a $44 \mathrm{mg} / \mathrm{L} \mathrm{CaCO}_{3}, \mathrm{pH}$ entre 7,3 e 7,6 e temperatura a $25 \pm 1^{\circ} \mathrm{C}$. O fotoperíodo foi controlado em 12 horas de claro e 12 horas de escuro. Os organismos foram alimentados uma vez ao dia com a ração comercial Tetramim com $97 \%$ de proteína

\section{Ensaio Experimental}

\section{Teste de toxicidade crônica}

Teste de toxicidade crônica por 21 dias em regime semiestático, ou seja, com troca total da solução a cada 72 horas, seguindo as recomendações da OECD (2009). A concentração utilizada foi baseada na legislação brasileira - Resolução CONAMA no 357/05 (BRASIL, 2005) - para rios de Classe 2: $9 \mu \mathrm{g} / \mathrm{L}$ de cobre dissolvido e $25 \mu \mathrm{mg} / \mathrm{L}$ de níquel total.

Foram selecionados 8 indivíduos (4 machos e 4 fêmeas) para a realização da análise histológica para cada grupo experimental com cobre (ou níquel), 8 indivíduos controle e 8 para reposição de perdas ( 4 para cobre e 4 para níquel), totalizando 24 organismos-teste $(n=24)$, considerando o grupo controle, o tratamento com cobre e o tratamento com níquel.

Após o tempo de exposição, foram selecionados organismos-teste aleatoriamente e eutanasiados em freezer com gelo. Posteriormente, foram pesados em balança analítica (Marte - AY220, Brasil) e medidos com o auxílio de um paquímetro, e então foram descartadas as nadadeiras e a cauda bem como foi feito um corte na transversal na porção inferior até a altura da cabeça. bruta. A manutenção da limpeza do aquário foi feita com esponja a cada 15 dias, podendo variar dependendo das condições do aquário, removendo os resíduos decantados. Dentro do aquário continha carvão ativado no filtro, cerâmicas para a formação de biofilme, removedor de amônia Amonclean, o qual era alocado próximo à saída do filtro de água, de modo que o removedor se mantivesse em movimento junto a água, e um cilindro esponjoso na extremidade de um tubo de plástico acoplado a uma bomba de ar, a fim de manter o nível de oxigênio.

Para o processo de fixação, utilizou-se formaldeído (37\%), sendo $10 \mathrm{~mL}$ de formaldeído e $90 \mathrm{~mL}$ de água destilada. Foram colocados 3 organismos por pote âmbar, de maneira que fosse mantida a proporção 9:1 de fixador em relação ao tecido, e então foram deixados em temperatura ambiente $\left(25^{\circ} \mathrm{C}\right)$ durante 18 horas.

Após esse período, o formol foi retirado com água corrente e os organismos foram colocados em álcool $70 \%$ para aguardar a etapa de processamento do tecido feito pelo equipamento San Pietro (O Patologista, Brasil).

Para o processo de coloração, as lâminas foram mantidas na estufa a $60^{\circ} \mathrm{C}$ durante cerca de 20 minutos para derreter o excesso de parafina. Após esse período, realizou-se uma série de submersões manuais para coloração hematoxilina e eosina (HE). Ao final do processo de coloração, as lâminas foram analisadas no microscópio óptico de luz (MLW - Junior Lab, Alemanha) e posteriormente foram selecionadas as lâminas para foto no microscópio óptico com captura de imagem (Leica DME) por meio do software LAS V.3.8. 


\section{Análise dos dados}

Para a análise histopatológica do fígado, foram usadas informações baseadas na literatura (FERNANDES et al., 2008; GAYÃO, 2009; PEREIRA, 2014; CORRÊA, 2016; ALKIMIN, 2016). Enquanto para a análise de interferência endócrino foi utilizado o protocolo da OECD para interferentes endócrinos (Guidance Document for the Diagnosis of Endocrine-Related Histopathology of Fish Gonads, 2009) e as alterações: inibição da gametogê- nese e maturação através da degeneração das células germinativas, inflamação, fibrose, picnose, presença de vacúolos, hipertrofia ou hiperplasia das células, descritas no livro Histological Analysis of Endocrine Disruptive Effects in Small Laboratory Fish (DIETRICH \& KRIEGER, 2009). Em ambos, as análises foram baseadas principalmente na característica distinta entre o grupo controle e o tratamento com os metais cobre e níquel.

\section{RESULTADOS}

\section{Tecido hepático após 21 dias de exposição ao cobre e ao níquel}

As análises das lâminas de cobre e níquel controle mostraram um padrão normal de distribuição dos hepatócitos. Foi possível observar vasos sanguíneos, células sanguíneas e cordões hepáticos íntegros, núcleo uniforme central com alta basofilia e citoplasma com pequenas vesículas e alta acidofilia, sem sinais de degeneração ou hipertrofia/hiperplasia das células. Porém, os organismos expostos cronicamente aos metais mostraram alterações histopatológicas similares em ambos os tecidos (Figuras 1 e 2).

É notável a diferença entre os cortes histológicos dos grupos controle e do tratamento com os metais.
Foi possível ver que o parênquima estava íntegro. Ou seja, os hepatócitos estão dispostos de maneira uniforme, sem sinais de vacuolização, com a membrana citoplasmática bem definida. Ao observar a histologia dos cortes para os tratamentos com os metais, nota-se grande vacuolização, em que os espaços entre os hepatócitos estão maiores, sendo possível ver grande porção branca na lâmina, a qual apresentou-se quase completamente corada. No caso do cobre (Figura 3), a perda da integridade citoplasmática aparentou ser maior, com mais pontos de vacuolização e grande degeneração em parte do tecido, quando comparado ao tecido exposto ao níquel (Quadro 1).
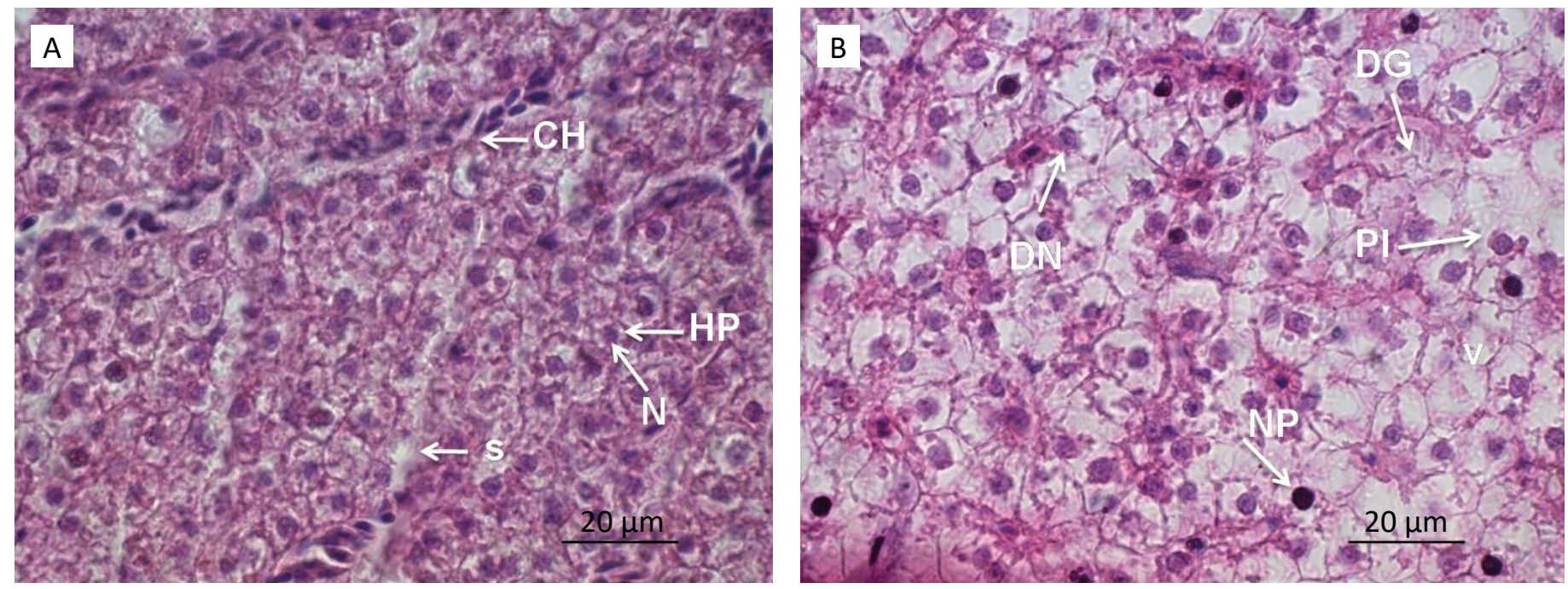

CH: cordões hepáticos; HP: hepatócitos; NP: núcleo picnótico; DG: degeneração;

$\mathrm{N}$ : núcleo; S: sinusoide; V: vacuolização; PI: perda da integridade citoplasmática.

Figura 1 - Corte histológico comparativo de fígado de Danio rerio do grupo controle (A) e tratamento com níquel (B) (H\&E, $1.000 \mathrm{x})$. 
Ao observar os núcleos, nos grupos controle, eles estão ao centro do hepatócito e têm tamanhos muito similares. Já nos grupos do tratamento com metais é possível notar, em ambos, hipertrofia, quando são maiores do que o padrão, e atrofia, quando o núcleo parece ter diminuído. Em algumas porções das lâminas não é possível ver a presença de núcleo, o que pode indicar um processo de degeneração. Também são observados nú- cleos achatados e outros muito escuros, denominados núcleos picnóticos (Figura 2). A proporção de núcleos picnóticos nos grupos de tratamento com metal, especialmente em níquel (no qual foi mais evidente), foi muito maior do que no grupo controle (Figuras 1 e 2).

Foi possível constatar estagnação sanguínea nos vasos sanguíneos do tecido hepático. No grupo

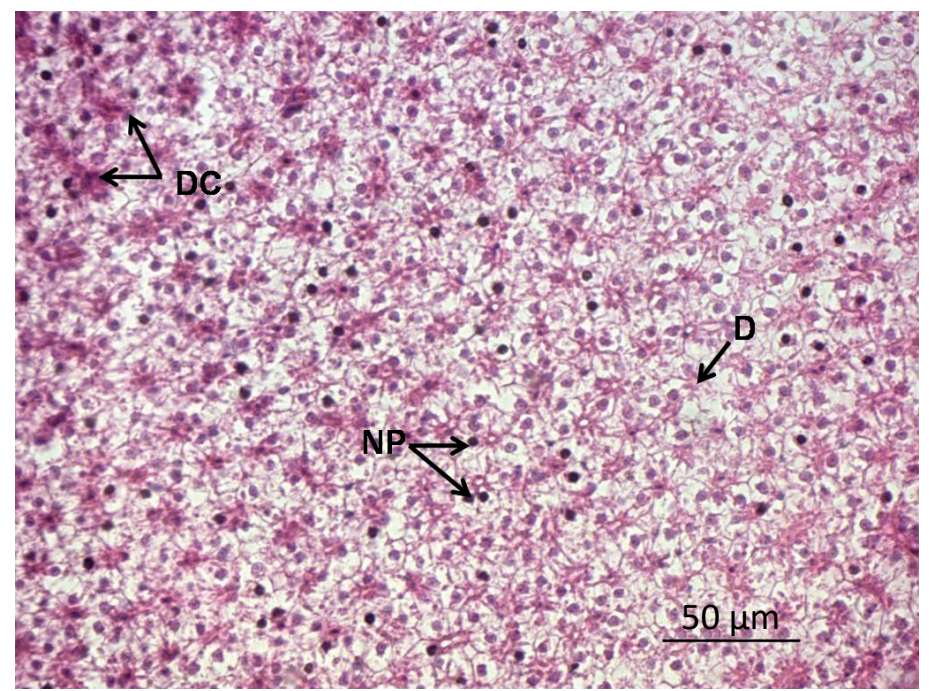

DC: desarranjo dos cordões hepáticos; NP: núcleo picnótico; D: degeneração.

Figura 2 - Corte histológico de fígado de Danio rerio do tratamento com níquel (H\&E, 400 x).
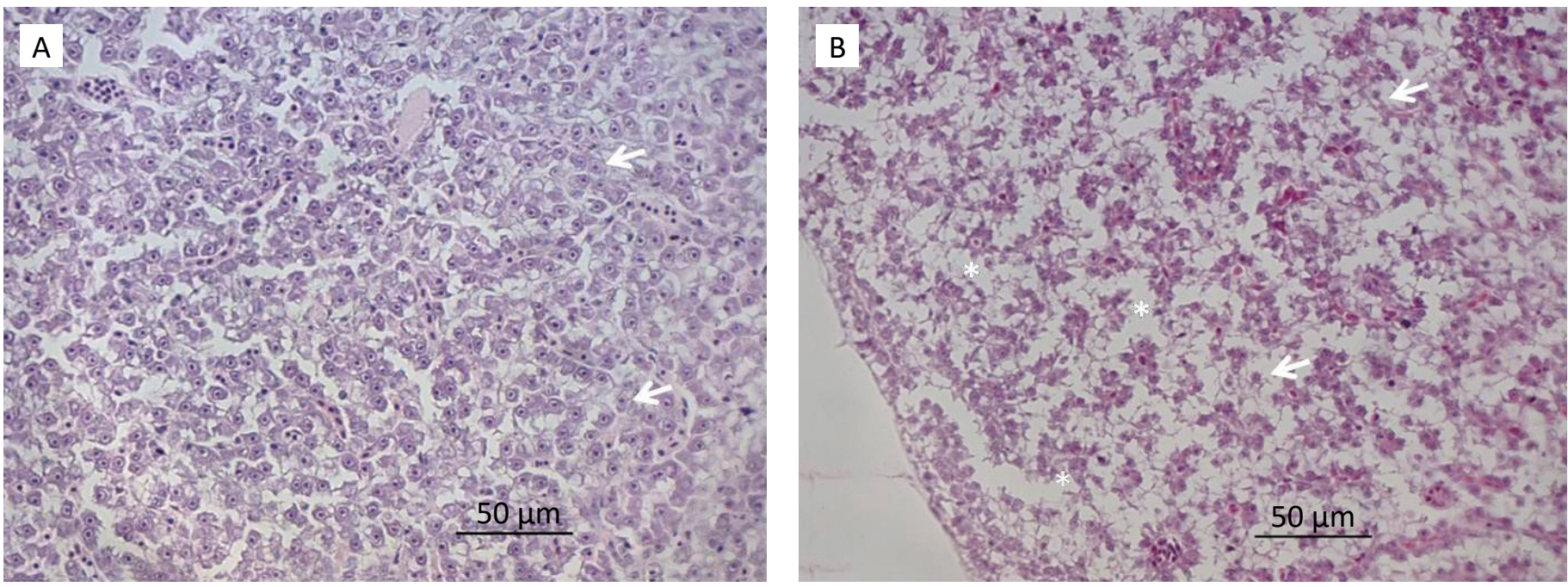

* degeneração do tecido.

Figura 3 - Corte histológico comparativo de fígado de Danio rerio do grupo controle (A) tratamento com Cobre (B) (H\&E, $400 \mathrm{x}$ ). (A) As setas mostram os hepatócitos com estrutura íntegra; (B) os hepatócitos com perda da integridade citoplasmática. 
controle, as células sanguíneas apresentavam-se mais espaçadas, sem acúmulo em uma porção da veia.
Os cordões hepáticos do grupo controle apresentaram-se alinhados e organizados. Já no tratamento repara-se o seu desarranjo (Figuras 1 e 2).

\section{Gônada masculina após 21 dias de exposição ao níquel}

As análises histológicas da gônada masculina do grupo controle mostraram um padrão normal de desenvolvimento, com todas as células germinativas - espermatogônia, espermatócito e espermátides - delimitados pelo espermatocisto.

No grupo controle era possível observar mais claramente as espermatogônias, mais coradas e dispostas de forma aglomerada. Os espermatócitos, derivados das espermatogônias, eram caracterizados por serem menores que as células anteriores e, comparativamen- te, com núcleo mais denso com pouco citoplasma visível. Essas eram as células mais abundantes da gônada masculina. As espermátides também foram vistas, sendo as menores células germinativas observáveis.

A análise histológica do tratamento com níquel detectou aumento na proporção das espermatogônias, quando comparado ao grupo controle (Figura 4).

As alterações foram analisadas e classificadas de acordo com as normas da OECD (2009), como segue a Quadro 2.

Quadro 1 - Respostas morfológicas após exposição crônica dos metais cobre e níquel.

\begin{tabular}{|c|c|c|c|c|}
\hline Organismo & Metal & Concentração & Órgão & Biomarcadores histológicos \\
\hline Danio rerio & Grupo controle & 0 & Fígado & $\begin{array}{l}\text { Hepatócitos com núcleo centralizado } \\
\text { Hepatócitos dispostos de maneira uniforme } \\
\text { em todo o tecido } \\
\text { Núcleo arredondado } \\
\text { Vasos sinusoides } \\
\text { Citoplasma íntegro } \\
\text { Veia com células sanguíneas }\end{array}$ \\
\hline Danio rerio & Níquel & $25 \mu \mathrm{g} / \mathrm{L}$ & Fígado & $\begin{array}{l}\text { Hipertrofia do núcleo } \\
\text { Núcleo achatado } \\
\text { Degeneração } \\
\text { Vacuolização } \\
\text { Perda de integridade citoplasmática } \\
\text { Desorganização tecidual } \\
\text { Aumento dos núcleos picnóticos }\end{array}$ \\
\hline Danio rerio & Cobre & $9 \mu \mathrm{g} / \mathrm{L}$ & Fígado & $\begin{array}{l}\text { Hipertrofia do núcleo } \\
\text { Degeneração } \\
\text { Vacuolização } \\
\text { Perda de integridade citoplasmática } \\
\text { Desorganização tecidual } \\
\text { Núcleo não-uniforme } \\
\text { Aumento dos núcleos picnóticos }\end{array}$ \\
\hline
\end{tabular}



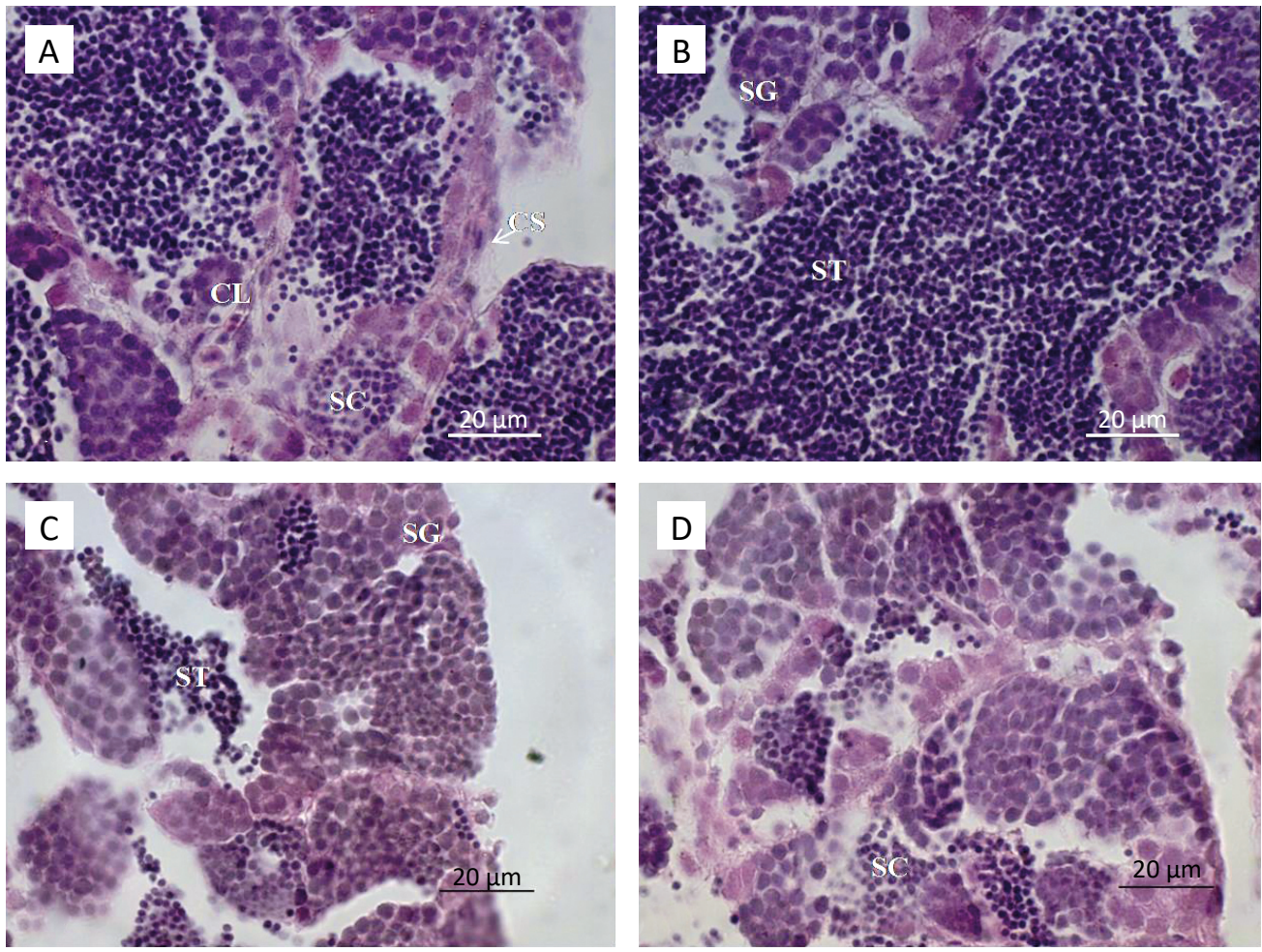

SG: espermatogônia; SC: espermatócito; ST: espermátide; CL: células de Leydig; CS: células de Sertoli.

Figura 4 - Corte histológico da Gônada masculina de Danio rerio grupo controle (A e B) e tratamento com níquel (C e D) (H\&E, 1.000 x).

Quadro 2 - Biomarcadores histológicos de gônadas masculinas após exposição ao níquel em de Danio rerio e o grau de severidade de acordo com as normas da Organização para a Cooperação e Desenvolvimento Econômico para interferentes endócrinos (OECD, 2009).

\begin{tabular}{|c|c|c|c|}
\hline & Diagnóstico primário & $\begin{array}{c}\text { Presença/ausência/ } \\
\text { não observável (NO) } \\
\text { da alteração (x/ V) }\end{array}$ & $\begin{array}{c}\text { Grau de } \\
\text { severidade } \\
(\mathrm{I}, \mathrm{II}, \mathrm{III}, \mathrm{IV})\end{array}$ \\
\hline 1 & Aumento da proporção de espermatogônias & $\mathrm{V}$ & ॥ \\
\hline 2 & Presença de ovário no testículo & $x$ & $x$ \\
\hline 3 & Aumento da degeneração testicular & $\checkmark$ & 1 \\
\hline \multirow[t]{2}{*}{4} & Hiperplasia/hipertrofia nas células de Leydig & $x$ & $x$ \\
\hline & Diagnóstico secundário & $\begin{array}{l}\text { Presença/ausência da } \\
\text { alteração }(x / v)\end{array}$ & $\begin{array}{c}\text { Grau de } \\
\text { severidade } \\
(\mathrm{I}, \mathrm{II}, \mathrm{III}, \mathrm{IV})\end{array}$ \\
\hline 1 & Diminuição da proporção de espermatogônias & $x$ & $x$ \\
\hline 2 & Fluido proteico vascular ou intersticial aumentado & NO & $x$ \\
\hline 3 & Desenvolvimento assíncrono da gônada & $\mathrm{V}$ & I \\
\hline 4 & Alterada proporção de espermatozoides ou espermatócitos & $\checkmark$ & II \\
\hline 5 & Estágio gonadal & NO & $x$ \\
\hline 6 & Inflamação granulomatosa & NO & $x$ \\
\hline
\end{tabular}




\section{DISCUSSÃO}

\section{Tecido hepático após 21 dias de exposição ao cobre e níquel}

A análise histopatológica do fígado tem sido utilizada para indicar alterações causadas por estresse ambiental por ser um órgão diretamente relacionado à biotransformação de xenobióticos, à excreção de metais-traço e ao metabolismo de hormônios sexuais (AU, 2004; FERNANDES et al., 2008; PEREIRA, 2014).

As características morfológicas dos grupos controle em padrões dentro da normalidade significam que não houve alterações morfológicas nas estruturas do fígado dos grupos controles de ambos os ensaios que pudessem comprometer o órgão a desempenhar sua função.

As alterações encontradas em ambos os metais, no presente estudo, como parênquima heterogêneo, sendo visto o deslocamento do núcleo, a vacuolização e degeneração citoplasmática e nuclear e a estagnação sanguínea, corroboram os estudos que demonstram alterações histopatológicas por meio de biomarcadores no fígado de peixes de diversas espécies, como: Liza saliens (FERNANDES et al., 2008), Oreochromis niloticus (GAYÃO, 2009), Astyanax altiparanae (PEREIRA, 2014), Prochilodus lineatus (CAMARGO \& MARTINEZ, 2007; PEREIRA, 2014) e Danio rerio (CORRÊA, 2016).

As lesões do fígado podem ser classificadas como não neoplásicas, as quais são indícios iniciais de toxicidade causada por agentes tóxicos, como as alterações encontradas no presente estudo, e neoplásicas, como adenoma hepatocelular, relacionado a tumores cancerígenos (FERNANDES et al., 2008).

A acumulação de lipídeos nos hepatócitos em peixes expostos a metais indica a exposição a componentes tóxicos que ocasionam injúria no fígado. A vacuolização pode aumentar o volume dos hepatócitos e indicar alta concentração de lipídeos e glicogênio, que prejudicam a atividade metabólica do órgão (FERNANDES et al., 2008; GAYÃO, 2009).

Os vacúolos no citoplasma contêm lipídeos e glicogênio. Este último é responsável por agir como uma reserva de glucose para suprir altas demandas energéticas, como no caso de estresse provocado por fatores externos. Ou seja, a vacuolização dos hepatócitos mostra sinal de um processo de degeneração que sugere dano metabólico (CAMARGO \& MARTINEZ, 2007).
A necrose, a hiperplasia e a vacuolização são respostas a ambientes severamente contaminados por metais (AU, 2004). Os pontos de necrose podem ser biomarcadores de exposição crônica em peixes (FERNANDES et al., 2008).

No presente estudo não foi possível observar sinais de estagnação da bile ou aumento de melanomacrófagos que poderiam significar importantes lesões relacionadas ao processo degenerativo e necrose, uma vez que a bile não estaria sendo liberada do fígado e os melanomacrófagos não poderiam desempenhar sua função antioxidante (CAMARGO \& MARTINEZ, 2007).

Nos estudos de Fernandes et al. (2008) foi visto que o parênquima estava heterogêneo provavelmente devido à exposição aos metais cobre e zinco.

Paris-Palacios et al. (2000) avaliaram perturbações causadas por cobre no organismo-teste Danio rerio submetido a teste crônico em concentrações subletais (40 e $140 \mu \mathrm{g}$ ). Como no presente estudo, foram observadas alterações nos hepatócitos, sendo sem núcleo ou com núcleos picnóticos, sinais de degeneração ao longo do parênquima, além de perturbações bioquímicas estudadas pelo autor. Vale a pena ressaltar que, no estudo de Paris-Palacios et al. (2000), os organismos, após serem submetidos ao teste crônico com cobre, foram expostos a água limpa, durante 14 dias (período de depuração), para observar sinais de recuperação, contudo não foi observada reversão às alterações encontradas.

Há menos informações a respeito do efeito tóxico do níquel em peixes em relação ao cobre, entretanto Kienle et al. (2008) observaram, em Danio rerio (larva e embrião), diminuição da atividade locomotora, retardo no tempo de eclosão e mortalidade, quando expostos a valores de 7,5 a $15 \mathrm{mg} / \mathrm{L}$ de níquel.

Topal et al. (2017), assim como no presente estudo, observaram alteração nos hepatócitos e sinais de degeneração no fígado de Oncorhynchus mykiss, quando expostos a concentrações de 1 a $2 \mathrm{mg} / \mathrm{L}$; e Athikesavan et al. (2006) verificaram sinais de necrose e degeneração das veias sanguíneas em Hypophthalmichthys molitrix expostos a concentrações de 5 a $7 \mathrm{mg} / \mathrm{L}$. 
O fígado não é o único órgão afetado pelos metais. Athikesavan et al. (2006) e Topal et al. (2017) também observaram alterações nas brânquias de peixes ocasionadas por exposição ao níquel. De maneira similar, Monteiro et al. (2009), em Oreochromis niloticus, Luzio et al. (2013), em Danio rerio, e Fonseca et al. (2017), em Luciobartus bocagei, Pseudochondrostoma sp. e Oncorhynchus mykiss, notaram alterações nas brânquias causadas por exposição ao cobre.

Driessnack et al. (2017) estudaram os efeitos do sinergismo entre cobre e níquel e notaram maior acumulação nos tecidos quando as duas substâncias estiveram presentes concomitantemente. Não somente com o cobre, mas a interação do níquel com o cromo, segundo Palaniappan e Karthikeyan (2009), mostrou maior poder de bioacumulação, o que leva a refletir sobre a escassez de estudos que são realizados considerando o sinergismo de duas substâncias, visto que no ambiente natural ocorrem transformações que podem aumentar a toxicidade dos metais.
O fígado é responsável por funções essenciais no organismo, como digestão e metabolismo de carboidratos (possuem enzimas sensíveis a poluentes). Alguns dos fatores importantes desempenhados pelo órgão são: produção de altas quantidades de amônia proveniente da desaminação dos aminoácidos; armazenamento de lipídeos e glicogênio, que são importantes em situação de estresse; formação da bile, que é responsável pelos sais biliares necessários para a digestão de gorduras, pigmentos biliares responsáveis pela quebra de produtos da hemoglobina, xenobióticos (especialmente metais) removidos do sangue; síntese de proteínas plasmáticas, como fibrinogênios (coagulação sanguínea) e albumina (mantém pressão osmótica do plasma, fonte de aminoácido, transporte de moléculas); síntese do colesterol; estabilizador de membranas celulares, lipoproteínas plasmáticas e mielina no sistema nervoso; secreção pancreática de enzimas digestivas e metabolismo de hormônios (HEATH, 1995). Portanto, alterações morfológicas no tecido hepático podem afetar significativamente seu funcionamento e, consequentemente, danificar o metabolismo vital de um organismo.

\section{Tecido gonadal masculino após $\mathbf{2 1}$ dias de exposição ao níquel}

As análises histológicas do tratamento com níquel, em comparação ao controle, mostraram aumento na proporção das espermatogônias, levando ao desenvolvimento assíncrono da gônada, ao aumento da degeneração do tecido gonadal e à alterada proporção de espermátides, sendo uma quantidade menor em relação ao grupo controle. De acordo com o documento da OECD, Guidance Document for the Diagnosis of Endocrine-Related Histopathology of Fish Gonads (2009), essas características enquadram o metal estudado como um interferente endócrino.

O aumento da proporção das espermatogônias pode significar que os organismos não estão conseguindo desenvolvê-las em espermatócitos.

As degenerações podem ser aumentadas de acordo com o tempo de exposição e podem ser revertidas em alguns casos. No presente estudo, não foi feito tratamento com água limpa após o tempo de exposição para ver o tempo de recuperação biológica desses indivíduos (GOHER et al., 2014).

Há poucos dados na literatura que relatam os efeitos dos contaminantes como interferentes endócrinos (ALKIMIN, 2016). Kienle et al. (2008) estudaram o organismo-teste
Danio rerio sob concentração de 7,5 a $15 \mathrm{mg} / \mathrm{L}$ de níquel e notaram o retardo no tempo de eclosão dos ovos, além de aumento nas taxas de mortalidade.

Apesar de poucos dados na literatura sobre alterações histopatológicas causadas pelo níquel em gônadas, há evidências de outros metais como interferentes endócrinos. Alkimin (2016) estudou os efeitos dos metais cádmio $(0,25$ e $1 \mu \mathrm{g} / \mathrm{L}$ ) e zinco (120 e $180 \mu \mathrm{g} / \mathrm{L}$ ) em Danio rerio e observou alterações que podem comprometer a capacidade reprodutiva da espécie em fêmeas. Entretanto, os sinais de degeneração encontrados em machos não foram significativos para comprometer a espécie.

Shalaby e Abd-El Migeed (2012) observaram alterações no epitélio germinativo, bem como diminuição das espermátides e de espermatozoides em Oreochromis niloticus expostos ao cádmio.

As alterações encontradas que definem uma substância como interferente endócrino podem levar a consequências na reprodução de um organismo, atrapalhando a perpetuação da espécie e, por isso, esse tipo de contaminante deve ser estudado (MONNERET, 2017). Há poucas informações na literatura sobre o efeito do níquel sobre os organismos aquáticos nessa vertente. 


\section{CONSIDERAÇÕES FINAIS E PERSPECTIVAS FUTURAS}

- O presente estudo sugere que as concentrações dos metais estudados (níquel $-25 \mu \mathrm{g} / \mathrm{L}$ - e cobre $9 \mu \mathrm{g} / \mathrm{L}$ ) apresentam efeitos tóxicos aos organismos aquáticos, mesmo quando expostos a concentrações subletais;

- O níquel é um metal que pode ser interferente endócrino, por ter provocado aumento da proporção das espermatogônias em machos de Danio rerio;

- Há poucos relatos na literatura sobre o potencial endócrino do níquel e cobre para organismos aquáticos. No presente estudo, a gônada masculina apresentou ter bons biomarcadores que indicam interferência endócrina nos organismos;

- Os biomarcadores histológicos mostraram-se ferramentas de identificação relativamente fácil, baixo custo em relação às demais respostas biológicas e há protocolos bem estabelecidos que permitem a sua reprodutibilidade por outros pesquisadores e garantem a relação entre lesões e contaminantes específicos no ambiente aquático;

- As alterações causadas nas gônadas e no fígado de indivíduos podem comprometer sua capacidade de sobrevivência e reprodução, afetando, assim, uma população e ou/comunidade.

\section{REFERÊNCIAS}

ASSOCIAÇÃO BRASILEIRA DE NORMAS TÉCNICAS (ABNT). Ecotoxicologia Aquática - Toxicidade crônica de curta duração - método de ensaios com peixes. Norma ABNT-NBR 15499. Rio de Janeiro: ABNT, 2015. 23p.

ACOSTA, D. S.; DANIELLE, N. M.; ALTENHOFEN, S.; LUZARDO, M. D.; COSTA, P. G.; BIANCHINI, A.; BONAN, C. D.; SILVA, R. S.; DAFRE, A. L. Copper levels at low levels impairs memory of adult zebrafish (Danio rerio) and affects swimming performance of larvae. Comparative Biochemistry and Physiology, Part C, v. 185-186, p. 122-130, 2016. https://doi. org/10.1016/j.cbpc.2016.03.008

ALKIMIN, G. D. Toxicidade de cádmio e zinco em Danio rerio: comparação entre valores permitidos em legislação para proteção da vida aquática e a potencial atuação como interferentes endócrinos. Dissertação (Mestrado em Ciências Ambientais) - Universidade Estadual Paulista "Júlio de Mesquita Filho", Sorocaba, 2016.

ARELLANO, J. M.; STORCH, V.; SARASQUETE, C. Histological changes and copper accumulation in liver and gills of the Senegales Sole. Solea senegalensis. Ecotoxicology and Environmental Safety, v. 44, n. 1, p. 62-72, 1999. https://doi. org/10.1006/eesa.1999.1801

ATHIKESAVAN, S.; VINCENT, S.; AMBROSE, T.; VEL MURUGAN, B. Nickel induced histopathological changes in the different tissues of freshwater fish. Hypophthalmichthys molitrix (Valenciennes). Journal of Environmental Biology, $\mathrm{v}$. 27, n. 2, p. 391-395, 2006.

AU, D. W. T. The application of histo-cytopathological biomarkers in marina pollution monitoring: a review. Marine Pollution Bulletin, v. 48, p. 817-834, 2004. https://doi.org/10.1016/j.marpolbul.2004.02.032

BRASIL. Conselho Nacional do Meio Ambiente. Resolução CONAMA no 357, de 17 de março de 2005. Dispõe sobre a classificação dos corpos de água e diretrizes ambientais para o seu enquadramento, bem como estabelece as condições e padrões de lançamento de efluentes, e dá outras providências. Diário Oficial [da República Federativa do Brasil], Brasília, 2005.

CAMARGO, M. M. P.; MARTINEZ, C. B. R. Histopathology of gills, kidney and liver of Neotropical fish caged in an urban stream. Neotropical Ichthyology, v. 5, n. 3, p. 327-336, 2007. http://dx.doi.org/10.1590/S1679-62252007000300013 
CORRÊA, C. E. S. Aspectos histológicos de gônadas e fígado de Danio rerio como potenciais biomarcadores indicativos de atuação de interferentes endócrinos do pesticida Chlorantraniliprole. Dissertação (Mestrado em Ciências Ambientais) Universidade Estadual Paulista "Júlio de Mesquita Filho", Sorocaba, 2016.

CRAIG, P. M.; WOOD, C. M.; McCLELLAND, G. B. Oxidative stress response and gene expression with acute copper exposure in zebrafish (Danio rerio). American Journal of Physiology - Regulatory Integrative Comparative Physiology, v. 293, n. 5, 2007. https://doi.org/10.1152/ajpregu.00383.2007

DANG, Z. C.; FLIK, G.; DUCOURET, B.; HOGSTRAND, C.; BONGA, S. E. W.; LOCK, R. A. C. Effects of copper on cortisol receptos and metallothionein expression in gills. Aquatic Toxicology, v. 51, p. 45-54, 2000. https://doi.org/10.1016/ S0166-445X(00)00102-8

DE BOECK, G.; VAN DER VEN, K.; HATTINK, J.; BLUST, R. Swimming performance and energy metabolism of rainbow trout, common carp and gibel carp respond differently to sublethal copper exposure. Aquatic Toxicology, v. 80, p. 92-100, 2006.

DIETRICH, D. R.; KRIEGER, H.O. Histological analysis of endocrine disruptive effects in small laboratory fish. New Jersey: John Wiley \& Sons, INC., Hoboken, 2009.

DOMINGUES, D. F.; BERTOLETTI, E. Seleção, manutenção e cultivo de organismos aquáticos. In: ZAGATTO, P. A.; BERTOLETTI, E. Toxicologia aquática: princípios e aplicações. São Carlos: RiMa Editora, 2006. p. 155-184.

DRIESSNACK, M. K.; JAMWAL, A.; NIYOGI, S. Effects of chronic exposure to waterborne copper and nickel in binary mixture on tissue-specific metal accumulation and reproduction in fathed minnow (Pimephales promelas). Chemosphere, v. 185, p. 964-974, 2017. https://doi.org/10.1016/j.chemosphere.2017.07.100

FERNANDES, C.; FONTAÍNHAS-FERNANDES, A.; ROCHA, E.; SALGADO, M. A. Monitoring pollution in Esmoriz-Paramos lagoon, Portugal: Liver histological and biochemical effects in Liza saliens. Environmental Monitoring Assessment, v. 145, p. 315-322, 2008. https://doi.org/10.1007/s10661-007-0041-4

FONSECA, A. R.; FERNANDES, L. F. S.; FONTAINHAS-FERNANDES, A.; MONTEIRO, S. M.; PACHECO, F. A. L. The impact of freshwater metal concentrations on the severity of histopathological changes in fish gills: A statistical perspective. Science of the Total Environment, v. 599-600, p. 217-226, 2017. https://doi.org/10.1016/j.scitotenv.2017.04.196

GAYÃO, A. L. B. A. Nutrição e reversão sexual de tilápia do nilo: parâmetros produtivos e estrutura do fígado. Dissertação (Doutorado em Aquicultura) - Universidade Estadual Paulista “Júlio de Mesquita Filho", Jaboticabal, 2009.

GOHER, M.; HASSAN, A. M.; ABDEL-MONIEM, I. A.; FAHMY, A. H.; EL-SAYED, S. Evaluation of surface water quality and heavy metal indices of Ismailia Canal, Nile River, Egypt. The Egyptian Journal of Aquatic Research, v. 40, n. 3, p. 225-233, 2014. https://doi.org/10.1016/j.ejar.2014.09.001

HANDY, R. D. Chronic effects of copper exposure versus endocrine toxicity: two sides of the same toxicological process? Comparative Biochemistry and Physiology, Part A 135, p. 25-38, 2003.

HAUSER-DAVIS, R. A.; BASTOS, F. F.; TUTON, B.; ROCHA, R. C.; PIERRE, T. S.; ZIOLLI, R. L.; ARRUDA, M. A. Z. Bile and liver metallothionein behavior in copper exposed fish. Journal of Trace Elements in Medicine and Biology, v. 28, p. 70-74, 2014.

HEATH, A. G. Water Pollution and Fish Physiology. 2ª ed. Florida: CRC Press/Lewis Publishers, 1995.

ISMAIL, N. A. H.; WEE, Y. S.; ARIS, A. Z. Multi-class of endocrine disrupting compounds in aquaculture ecosystems and health impacts in exposed biota. Chemosphere, v. 188, p. 375-388, 2017. https://doi.org/10.1016/j. chemosphere.2017.08.150 
KABIR, E. R.; RAHMAN, M. S.; RAHMAN, I. A review on endocrine disruptors and their possible impact on human health. Environmental Toxicology and Pharmacology, v. 40, p. 241-258, 2015. https://doi.org/10.1016/j.etap.2015.06.009

KIENLE, C.; KÖHLER, H. R.; FILSER, J.; GERHARDT, A. Effects of nickel chloride and oxygen depletion on behaviour and vitality of zebrafish (Danio rerio, Hamilton, 1822) (Pisces, Cypriniformes) embryos and larvae. Environmental Pollution, v. 152, p. 612-620, 2008. https://doi.org/10.1016/j.envpol.2007.06.069

LEITE, C. E.; MABONI, L. O.; CRUZ, F. F.; ROSEMBERG, D. B.; ZIMMERMANN, F. F.; PEREIRA, T. C. B.; BOGO, M. R.; BONAN, C. D.; CAMPOS, M. M.; MORRONE, F. B.; BATTASTINI, A. M. Involvement of purinergic system in inflammation and toxicity induced by copper in zebrafish larvae. Toxicology and Applied Pharmacology, v. 272, p. 681-689, 2013. https:// doi.org/10.1016/j.taap.2013.08.001

LUZIO, A.; MONTEIRO, S. M.; FONTAÍNHAS-FERNANDES, A. A.; PINTO-CARNIDE, O.; MATOS, M.; COIMBRA, A. M. Copper induced upregulation of apoptosis related genes in zebrafish (Danio rerio) Gill. Aquatic Toxicology, v. 128-129, p. 183-189, 2013. https://doi.org/10.1016/j.aquatox.2012.12.018

MONTEIRO, S. M.; SANTOS, N. M. S.; CALEJO, M.; FONTAÍNHAS-FERNANDES, A.; SOUSA, M. Copper toxicity in gills of the teleost fish Oreochromis niloticus: Effects in apoptosis induction and cell proliferation. Aquatic Toxicology, v. 94, p. 219-228, 2009. https://doi.org/10.1016/j.aquatox.2009.07.008

MONNERET, C. What is an endocrine disruptor? Comptes Rendus Biologies, v. 340, p. 403-405, 2017. https://doi. org/10.1016/j.crvi.2017.07.004

ORGANISATION FOR ECONOMIC CO-OPERATION AND DEVELOPMENT (OECD). Guidance document on the diagnosis of endocrine-related histopathology in fish gonads. Series on Testing and Assessment: Testing for Endocrine Disrupters No 123. Paris: OECD Publishing, 2009.

PALANIAPPAN, P. R.; KARTHIKEYAN, S. Bioaccumulation and depuration of chromium in the selected organs and whole body tissues of freshwater fish Cirrhinus mrigala individually and binary solutions with nickel. Journal of Environmental Sciences, v. 21, p. 229-236, 2009. https://doi.org/10.1016/S1001-0742(08)62256-1

PARIS-PALACIOS, S.; BIAGIANTI-RISBOURG, S.; VERNET, G. Biochemical and (ultra)structural hepatic perturbations of Brachydanio rerio (Teleostei, Cyprinidae) exposed to two sublethal concentrations of copper sulfate. Aquatic Toxicology, v. 50, p. 109-124, 2000. http://dx.doi.org/10.1016/S0166-445X(99)00090-9

PALERMO, F. F.; RISSO, W. E.; SIMONATO, J. D.; MARTINEZ, C. B. R. Bioaccumulation of nickel and its biochemical and genotoxic effects on juveniles of the neotropical fish Prochilodus lineatus. Ecotoxicology and Environmental Safety, v. 116, p. 19-28, 2015. http://dx.doi.org/10.1016/j.ecoenv.2015.02.032

PEDROZO, M. F. M.; LIMA, I. V. Ecotoxicologia do cobre e seus compostos. Salvador: Cadernos de Referência Ambiental, 2001. v. 2. $128 p$.

PEREIRA, B. F. Análise dos efeitos da exposição a ambientes poluídos na morfologia e no envelhecimento precoce, de brânquias e fígado em peixes. Dissertação (Doutorado em Biologia Celular e Molecular) - Universidade Estadual Paulista "Júlio de Mesquita Filho", Rio Claro, 2014.

PREDA, C.; UNGUREANU, M. C.; VULPOI, C. Endocrine disruptors in the environment and their impact on human health. Environmental Engineering and Management Journal, v. 11, n. 9, p. 1697-1706, 2012.

PYLE, G.; COUTURE, P. Nickel. In: WOOD, C.; FARRELL, A.; BRAUNER, C. Homeostasis and toxicology of essential metals. Academic Press. 1a ed. v. 31, part A, p. 1-497, 2012.RECK, B.; MÜLLER, D. B.; ROSTKOWSKI, K.; GRAEDEL, T. E. Anthropogenic nickel cycle: Insights into use, trade and recycling. Environmental Science Technology, v. 42, p. 3394-3400, 2008. 
ROSA, A. H.; FRACETO, L. F.; MOSCHINI-CARLOS, V. Meio ambiente e sustentabilidade. Porto Alegre: Bookman, 2011.

SANCHEZ, D. C. O. Desreguladores endócrinos na indução da vitelogenina em peixes nativos. 71 f. Dissertação (Mestrado em Farmacologia) - Setor de Ciências Biológicas, Universidade Federal do Paraná, Curitiba, 2006.

SARGenTELlI, V.; MAURO, A. E.; MASSABNI, A. C. Aspectos do Metabolismo do Cobre no Homem. Química Nova, v. 19, n. 3, p. 290-293, 1995.

SHALABY, F. M.; ABD-EL MIGEED, H. Impact of environmental contaminants on the testes of Oreochromis niloticus with special reference to ultrastructure of spermatozoa in Lake Manzala (Egypt). Journal of Environmental \& Analytical Toxicology, v. 2, n. 6, 2012. https://doi.org/10.4172/2161-0495.S1.002

TOPAL, A.; ATAMANALP, M.; ORUÇ, E.; EROL, H. S. Physiological and biochemical effects of nickel on rainbow trout (Oncorhynchus mykiss) tissues: Assessment of nuclear factor kappa B activation, oxidative stress and histopathological changes. Chemosphere, v. 166, p. 445-452, 2017. https://doi.org/10.1016/j.chemosphere.2016.09.106

UNITED STATES ENVIRONMENTAL PROTECTION AGENCY (USEPA). Endocrine Disruptors. Official Website of the Government of United States, 2017. Disponível em: https://www.epa.gov/endocrine-disruption. Acesso em: 27 jul. 2018.

WORLD HEALTH ORGANISATION (WHO). Guidelines for Drinking-water quality. 4a ed. Genebra: WHO, 2011.

ZHENG, G.; LIU, C.; SUN, J.; FENG, Z.; CHENG, C. Nickel-induced oxidative stress and apoptosis in Carassius auratus liver by JNK pathway. Aquatic Toxicology, v. 147, p. 105-111, 2014. https://doi.org/10.1016/j.aquatox.2013.12.015 